\title{
RNA Primer Extension Hinders DNA Synthesis by Escherichia coli Mutagenic DNA Polymerase IV
}

\section{OPEN ACCESS}

Edited by:

Michael Sauer,

University of Natural Resources and Life Sciences, Vienna, Austria

Reviewed by:

Hua Xiang,

Institute of Microbiology (CAS), China Graham Charles Walker,

Massachusetts Institute of Technology, USA

*Correspondence:

Veronica G. Godoy

v.godoycarter@northeastern.edu

tPresent address:

Ida Lin,

Fred Hutchinson Cancer Research

Center, Seattle, WA, USA

Verena Belt,

Leibniz Universität Hannover,

Hannover, Germany;

Tiziana M. Cafarelli,

Department of Cancer Biology, Center

for Cancer Systems Biology,

Dana-Farber Cancer Institute, Boston,

MA, USA;

Department of Genetics, Harvard

Medical School, Boston, MA, USA

Specialty section:

This article was submitted to Microbial Physiology and Metabolism, a section of the journal

Frontiers in Microbiology

Received: 16 December 2016

Accepted: 13 February 2017

Published: 01 March 2017

Citation:

Tashjian TF, Lin I, Belt V, Cafarelli TM and Godoy VG (2017) RNA Primer Extension Hinders DNA Synthesis by Escherichia coli Mutagenic DNA Polymerase IV.

Front. Microbiol. 8:288.

doi: 10.3389/fmicb.2017.00288
Tommy F. Tashjian, Ida Lin', Verena Belt', Tiziana M. Cafarellit and Veronica G. Godoy*

Godoy Lab, Department of Biology, Northeastern University, Boston, MA, USA

In Escherichia coli the highly conserved DNA damage regulated dinB gene encodes DNA Polymerase IV (DinB), an error prone specialized DNA polymerase with a central role in stress-induced mutagenesis. Since DinB is the DNA polymerase with the highest intracellular concentrations upon induction of the SOS response, further regulation must exist to maintain genomic stability. Remarkably, we find that DinB DNA synthesis is inherently poor when using an RNA primer compared to a DNA primer, while high fidelity DNA polymerases are known to have no primer preference. Moreover, we show that the poor DNA synthesis from an RNA primer is conserved in DNA polymerase Kappa, the human DinB homolog. The activity of DinB is modulated by interactions with several other proteins, one of which is the equally evolutionarily conserved recombinase RecA. This interaction is known to positively affect DinB's fidelity on damaged templates. We find that upon interaction with RecA, DinB shows a significant reduction in DNA synthesis when using an RNA primer. Furthermore, with DinB or DinB:RecA a robust pause, sequence and lesion independent, occurs only when RNA is used as a primer. The robust pause is likely to result in abortive DNA synthesis when RNA is the primer. These data suggest a novel mechanism to prevent DinB synthesis when it is not needed despite its high concentrations, thus protecting genome stability.

Keywords: DNA polymerase IV, DinB, RecA, protein-protein interactions, DNA replication

\section{INTRODUCTION}

The SOS gene network in Escherichia coli is a highly conserved global stress response induced by DNA damage caused by either exogenous sources or byproducts of cellular metabolism (Horii et al., 1981; Goodman and Woodgate, 2013). The SOS response is upregulated when single-stranded DNA (ssDNA), the signal of DNA damage, accumulates and is bound by the protein RecA. The interaction between RecA and ssDNA results in a new activity for the RecA nucleoprotein filament or RecA*. The newly acquired co-protease activity of RecA* promotes the autocleavage of LexA,

Abbreviations: All pyr template, DNA template with in which all purines are mutated to pyrimidines; Naïve DinB, DinB that has not been in contact with RecA; DinB:RecA, a mix of proteins containing a 1:1 molar ratio of DinB to RecA; DinB, DNA polymerase IV; DNA*:DNA, fluorescently labeled DNA primer annealed to a DNA template; DNA:DNA, unlabeled DNA primer annealed to a DNA template; C3G template, DNA template with a C-to-G mutation across from the third nucleotide insertion site; FE, fully extended primer; Lesion template, DNA template with a 3-deaza-3-methyladenine lesion across from the first nucleotide insertion site; RNA*:DNA, fluorescently labeled RNA primer annealed to a DNA template; Pol III $\alpha$, alpha subunit of DNA polymerase III; TLS, translesion synthesis; 3d-meA, 3-deaza-3-methyladenine; +3 , primer with three nucleotide insertions. 
the SOS global transcriptional repressor (Little et al., 1980; Horii et al., 1981). LexA repressor cleavage de-represses expression of $>40$ genes comprising the network, including the $\operatorname{din} B, \operatorname{rec} A$, and lexA genes themselves (Fernandez De Henestrosa et al., 2000; Courcelle et al., 2001; Khil and Camerini-Otero, 2002; Friedberg et al., 2006). RecA, a multifunctional protein, plays essential roles in maintaining genomic integrity; its activities include mediating strand exchange in homologous recombination (Chintapalli et al., 2013), coordinating the access of DNA polymerases at the replication fork (Indiani et al., 2013), and slowing down DNA replication upon DNA damage (Tan et al., 2015).

DNA polymerase IV, an evolutionarily conserved error-prone DNA polymerase, is among the very first proteins upregulated during the SOS response as a consequence of the weak affinity between the LexA repressor and its binding site on the $\operatorname{din} B$ promoter (Fernandez De Henestrosa et al., 2000; Courcelle et al., 2001). DinB is well-known for its ability to catalyze TLS, during which it bypasses specific DNA lesions on the template strand that would otherwise result in lethal replication fork stalling (Goodman, 2002; Friedberg et al., 2006; Jarosz et al., 2009). TLS is enabled by DinB's open active site, which allows the enzyme to accommodate DNA lesions, though at the forfeiture of reliable geometric basepair checking (Yang, 2003; Jarosz et al., 2009). DinB is thus error-prone [at least a 10-fold higher mutation frequency on undamaged DNA compared to high fidelity DNA polymerase III's (Tang et al., 2000)], possessing a mutational signature of -1 frameshifts and specific base pair substitutions (Kim et al., 2001; Nohmi, 2006). Accordingly, DinB activity has been associated with acquisition of bacterial antibiotic resistance (Bull et al., 2001; Cirz et al., 2005).

Despite LexA regulation, the basal level of DinB in E. coli is still relatively high [ 250 nM (Kim et al., 2001)] when compared to other DNA polymerases in the cell [e.g., $40 \mathrm{nM}$ for the catalytic alpha subunit of DNA polymerase III (Pol III $\alpha$ ) (Maki et al., 1985)]. As a consequence, other means of regulating DinB activity are physiologically important. One of these is the formation of a higher-order protein complex with RecA and a dimer of full-length UmuD, an accessory subunit. While in this complex, the enzyme generates fewer -1 frameshift mutations and has increased catalytic activity on properly aligned templates (Godoy et al., 2007). Structural docking based on peptide interaction data suggests that the binding of RecA and UmuD encloses the DinB active site. The interactions likely reduce DinB-mediated mutagenesis by restricting template looping that is required for frameshift events (Godoy et al., 2007). Recently, we showed that DinB also forms complexes in vivo exclusively with RecA (Cafarelli et al., 2013), and that this positively affects DinB fidelity (Cafarelli et al., 2014).

The other critical regulatory interaction made by DinB is with the beta processivity clamp, a key player of the cell's replication machinery (Wagner et al., 2000). The beta clamp increases the processivity of various DNA polymerases (Wagner et al., 2000; Maor-Shoshani and Livneh, 2002; Vidal et al., 2004) and is partially responsible for coordinating polymerase switching at the replication fork (Kath et al., 2014). DinB's affinity for the beta clamp is lower than that of Pol III $\alpha\left[K_{\mathrm{D}}=460 \mathrm{nM}\right.$ (Heltzel et al., 2012) and $108 \mathrm{nM}$ (Heltzel et al., 2009) respectively]. It is possible that under non-DNA damaging conditions, this $\sim 4$ fold difference contributes to preventing DinB from accessing the replication fork instead of Pol III $\alpha$, though there is no direct evidence that speaks to this. However, upon DNA damage DinB is clearly the most abundant DNA polymerase in the E. coli cell at a concentration of approximately $2500 \mathrm{nM}$ (Kim et al., 2001). Remarkably, in the DNA damage induced cell, the ratio of DinB:Pol III $\alpha$ is at approximately 60:1 (Maki et al., 1985; Kim et al., 2001). Given that the relative affinity of the beta clamp for DinB is only approximately four times lower than that for Pol III $\alpha$ and that DinB is in such excess in the cell, other mechanisms are likely necessary to prevent DinB synthesis on undamaged DNA.

Here, we report that DinB performs poor DNA synthesis with RNA primers and that this synthesis is further impeded upon interaction with RecA. The mechanism of this inhibition of synthesis is through a seemingly robust pause that is independent of template and lesion and is likely to result in abortive DNA synthesis when RNA is the primer. Poor synthesis of DinB using RNA primers might represent a way to prevent DNA synthesis by DinB when it is not needed. Our data provide novel insight into the mechanisms of regulation of error-prone DinB, which will, in turn, permit a deeper understanding of the relationship between DNA damage, mutagenesis, and genomic stability.

\section{MATERIALS AND METHODS}

\section{Strains, Plasmids, and Oligonucleotides}

The strain TMC $\triangle \mathrm{T}$ : BL21-AI (Life Technologies, Carlsbad, CA, USA) $\triangle \operatorname{din} B, \Delta u m u D C, \Delta r e c A$, was used for protein purification, and was constructed by $\mathrm{P} 1$ transduction (Thomason et al., 2007) using as a host the BL21-AI $\Delta \operatorname{din} B, \Delta u m u D C$ strain (Cafarelli et al., 2013). The construction of the RecA overproducing plasmid (pILRecA) is described below while the DinB overproducing plasmid (pDFJ1) has been previously published (Jarosz et al., 2006). The TMC $\Delta \mathrm{T}$ strain with the overproducing plasmids was grown in Luria broth medium with ampicillin [TMC $\Delta \mathrm{T} / \mathrm{pDFJ} 1$ (Jarosz et al., 2006); $100 \mu \mathrm{g} / \mathrm{mL}$ ] or kanamycin (TMC $\Delta \mathrm{T} / \mathrm{pILRecA} ; 35 \mu \mathrm{g} / \mathrm{mL}$ ). Protein induction conditions are described below. All oligonucleotides used in this work are listed in Supplementary Table 1.

\section{Protein Purification}

The native DinB overproducer plasmid, pDFJ1 (Jarosz et al., 2006), was introduced by transformation into the TMC $\Delta \mathrm{T}$ strain. Native DinB was overexpressed by autoinduction (Studier, 2005; Cafarelli et al., 2013) and cells were lysed using a cell homogenizer (Cafarelli et al., 2013). DinB was purified by ion exchange and hydrophobic interaction chromatography as previously published (Beuning et al., 2006). This will be referred to as naïve DinB in this report, since it has never been in contact with RecA.

The plasmid overproducing RecA was constructed as follows: the recA gene was amplified by PCR using the plasmid pCA24N (Konola et al., 1998) as template. The recA gene-containing amplicon was cloned into the $\mathrm{pET}$ 
His6 TEV LIC cloning vector (plasmid 29653; Addgene, Cambridge, MA, USA) by ligation independent cloning (LIC). PCR cycling conditions were based on the melting temperature of primer pairs. Primer sequences are listed in Supplementary Table 1 . The resulting plasmid, pILRecA, was introduced by transformation into the TMC $\Delta \mathrm{T}$ strain. Cells were grown to saturation at $37^{\circ} \mathrm{C}$ in Luria broth medium with $35 \mu \mathrm{g} / \mathrm{mL}$ kanamycin and $0.05 \%$ (v/v) glucose. A $1 \mathrm{~L}$ culture of the same medium was inoculated with a 1:1,000 dilution from the saturated culture and grown at $37^{\circ} \mathrm{C}$ with agitation $(250 \mathrm{rpm})$ until it reached an OD600 of 0.7. Protein overexpression was then induced by adding $0.05 \%(\mathrm{v} / \mathrm{v})$ of $\mathrm{L}$-arabinose. The culture was incubated at $20^{\circ} \mathrm{C}$ with agitation as before for approximately $12 \mathrm{~h}$. Native naïve RecA (never in contact with DinB) was purified following a protocol previously described in Chen et al. (2008), but an approximate 1:15 (w/w, TEV protease/substrate) dilution of tobacco etch virus (TEV) protease (QB3 Macrolab, University of California, Berkeley, Berkeley, CA, USA) was used to cleave the His-tag from the RecA preparations. Purity of all proteins was determined by SDS-PAGE (Supplementary Figure 1).

\section{Primer Extension Assays}

Primer extension assays were carried as previously described (Cafarelli et al., 2013) using Cy3 5' labeled DNA or RNA primers annealed to various DNA templates (Supplementary Table 1 and Figure 1A). We used undamaged templates containing adenine (A) at the primer-template junction as well as a lesioncontaining template with a 3-deaza-3-methyladenine (3d-meA) lesion at the same position (Supplementary Table 1). Reactions contained a mixture of $500 \mu \mathrm{M}$ dNTPs (Takara, Otsu, Shiga, Japan), buffer and similar concentrations of the different DNA polymerases. For DinB:RecA reactions, naïve $\operatorname{DinB}$ and RecA were incubated in buffer SA [50 mM Hepes, $10 \%$ glycerol (v/v), $2 \mathrm{mM}$ 2-mercaptoethanol, $\mathrm{pH}$ 7.5] at a 1:1 molar ratio at room temperature for $1 \mathrm{~h}$ before $0.6 \mu \mathrm{M}$ were added to the primer extension reaction mix. Polymerase Kappa was a gracious gift of Janice Pata (Wadsworth Center, NYS Department of Health) and DNA polymerase I was obtained from New England Biolabs (Ipswich, MA, USA). The undamaged C3 DNA template (Supplementary Table 1) was used unless otherwise indicated. All reactions were performed in triplicate and direct comparisons were made only of samples separated in the same gel. Percent full extension was calculated as the fraction of the FE product divided by the total obtained from all products (Figure 1). Percent total extension was calculated as the fraction of extended products minus the primer divided by the total obtained from all products (Figure 3).

\section{RESULTS}

\section{Naïve DinB extends Poorly from an RNA Primer}

To our knowledge there is no information published regarding DinB's ability to perform DNA synthesis using an RNA primer. It is known that in vitro $\mathrm{DinB}$ considerably slows DNA replication by Pol III $\alpha$ specifically on the lagging strand of synthesis (Indiani et al., 2009) and can switch with Pol III $\alpha$ at the replication fork during DNA synthesis (Heltzel et al., 2009, 2012). Due to DinB's high intracellular concentration [lowest levels: $250 \mathrm{nM}$ (Kim et al., 2001), compared to $40 \mathrm{nM}$ of Pol III $\alpha$ (Maki et al., 1985)], and the high availability of RNA primers to copy the lagging strand, we were interested in assessing DinB's inherent ability to carry out DNA synthesis using RNA primers.

We first used naïve DinB, which has never been in contact with RecA, to measure extension of a fluorescently labeled DNA or RNA primer annealed to the same unlabeled DNA template (Figure 1A). The reactions conditions and enzyme concentrations were consistent for primer extension reactions involving DNA or RNA primers. The products of these reactions were then examined by denaturing gel electrophoresis. We did not observe a significant difference between DNA and RNA primer extension in experiments with the high fidelity DNA polymerase I (Supplementary Figure 2). In contrast, we find that naïve DinB extended significantly less from an RNA than from a DNA primer (Figure 1B). Remarkably, we find that this property is conserved in DNA Pol Kappa (Figure 1C), the human homolog of DinB. We also noted a prominent band at the third nucleotide insertion ( +3 site, see +3 in Figure 1B) only in DinB's RNA primer extension products. The synthesis beyond this third addition was significantly diminished as compared to synthesis from a DNA primer (compare bands above +3 in lanes 2 and 4 , Figure 1B).

\section{Interaction with RecA Further Hinders DinB's Synthesis Using RNA Primers}

We have previously shown that DinB and RecA co-purify (Cafarelli et al., 2013) and that their interaction enhances DinB's fidelity (Cafarelli et al., 2014). We investigated whether RecA interaction also affects DinB's extension of RNA primers. We find that, remarkably, DinB:RecA's primer preference (i.e., difference between full extension using DNA or RNA primers) is significantly higher than that of naïve DinB. While RecA may be capable of binding ssDNA that is present in the template, we have previously shown that RecA in a 1:1 molar ratio with DinB does not inhibit DinB activity with a DNA primer [(Cafarelli et al., 2014), also compare lane 2 in Figure $\mathbf{1 B}$ to lane 1 in Figure 1D)]. Thus, it is unlikely that RecA's ssDNA binding is responsible for reduced $\operatorname{DinB}$ activity in the RNA primer experiments (Figure 1D). Notably, the prominent band at the third nucleotide insertion that is observed in the naive DinB extension assays was also seen here (compare +3 : lane 4 in Figure 1B and lane 2 Figure 1D).

We noticed that mixing DinB and RecA in a 1:1 molar ratio has a significant effect on DinB's full extension (compare FE band in Figure 1B, lane 4 and Figure 1D, lane 2). However, DinB interaction with RecA had little effect on the addition of the first three nucleotides (compare +3 band and below in Figure 1B, lane 4 and Figure 1D, lane 2), which accounted for most of the extension products observed in these reactions. As the uninduced RecA concentration in E. coli is approximately fourfold higher than that of DinB (Salles and Paoletti, 1983; Kim et al., 2001), 


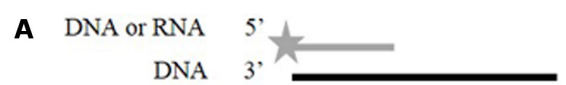

B $\quad$ DNA*: DNA RNA*: DNA

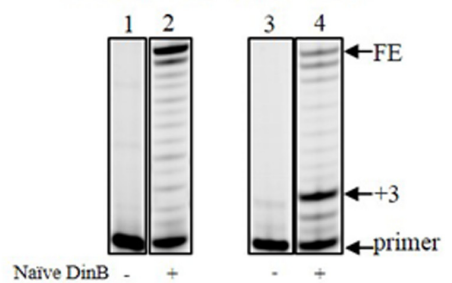

C DNA*: DNA RNA*:DNA

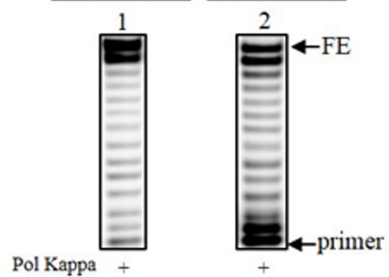

D DNA*: DNA RNA*: DNA

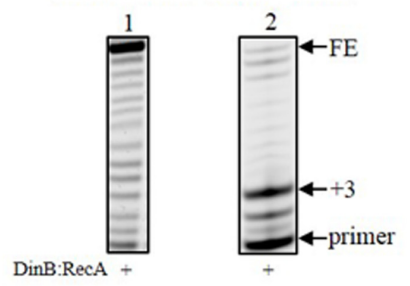

E

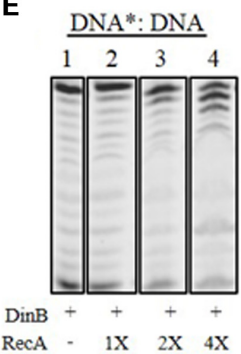

RNA*: DNA

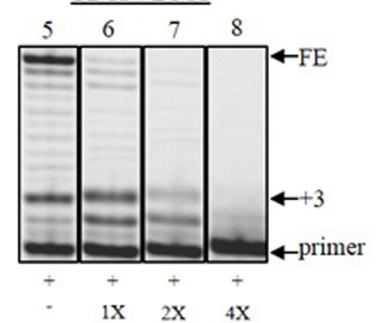

DNA primer

RNA primer
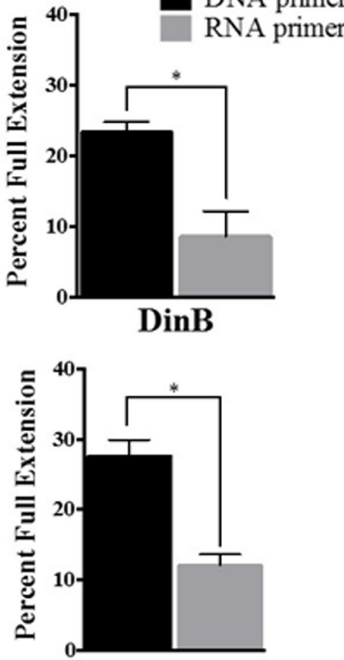

Pol Kappa
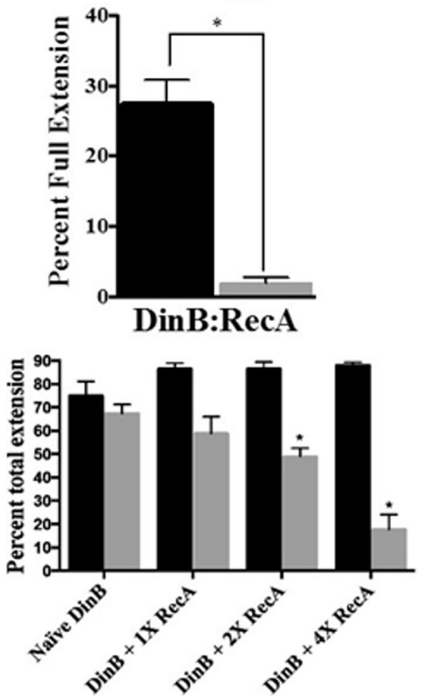

FIGURE 1 | Interaction with RecA further hinders DinB's inherently poor RNA primer extension. (A) Depiction of the primer extension assays carried out in the current work. The fluorescently labeled DNA or RNA primer is shown as a gray line with a star in the $5^{\prime}$ end. The DNA template is shown as a black straight line. The enzymes used are added to the reaction with the depicted substrate, which will extend from the primer. The primer extension assay products are separated in a denaturing acrylamide gel. Only extended products are observed under these conditions (B) Shown are the extension products resulting from the activity of $0.6 \mu \mathrm{M}$ naïve DinB separated on a denaturing acrylamide gel or (C) DNA polymerase Kappa. Also shown is the quantification of the percent of full extension, calculated as indicated in Section "Materials and Methods." These graphs show a twofold difference in DinB or Pol Kappa DNA primer extension compared to RNA primer extension. * Indicated $p$-value < 0.05. (D) The DinB:RecA was formed by incubating the DinB and RecA proteins in a 1:1 molar ratio at room temperature for $1 \mathrm{~h}$ (see Materials and Methods). Extension products resulting from the activity of $0.6 \mu \mathrm{M}$ DinB:RecA were quantified and show a significant reduction in full RNA primer extension as compared to naive DinB. * Indicated $p$-value $<0.05$. (E) RecA and DinB were incubated, as in (D), with increasing molar ratios. Higher concentrations of RecA significantly inhibit DinB's total extension using RNA primers while having little effect on DinB's total extension using DNA primers. * Indicated $p$-value $<0.05$ when comparing to extension by naïv DinB. All primer extension experiments were performed in triplicate. The quantification was carried out using extension products separated on the same gel. Images depict representative examples. Error bars indicate mean \pm standard error. DNA*: DNA, fluorescently labeled DNA primer annealed to the DNA template; RNA*: DNA, fluorescently labeled RNA primer annealed to the DNA template; FE, fully extended primer band; +3 , primer plus three nucleotide insertions band.

we sought to determine how higher RecA concentration would alter DinB's extension. To account for the first three-nucleotide insertions, we compared in these experiments the percent total extension (i.e., the quantification of all extension products divided by the quantification of the extension products plus the primer). Interestingly, increasing concentrations of RecA significantly inhibits DinB's total extension using RNA primers, while having no significant effect on its extension using DNA 
A
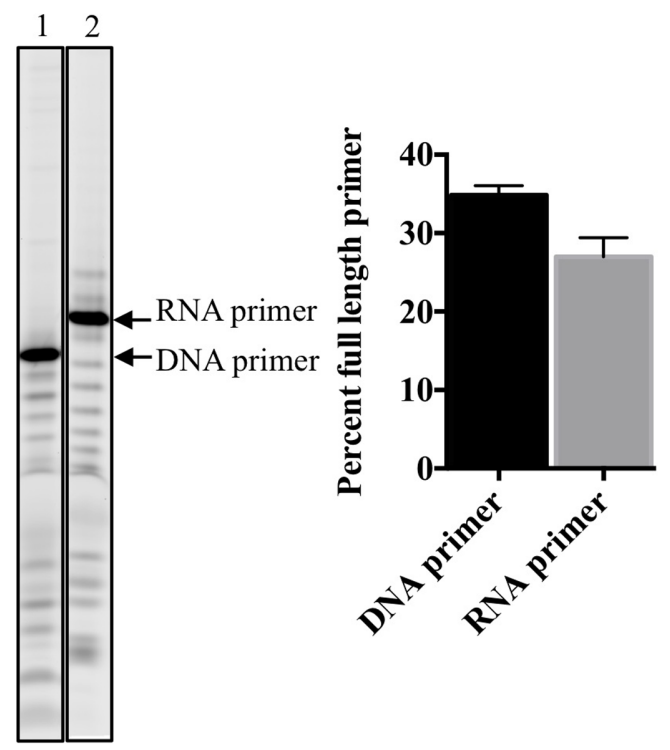

B

B
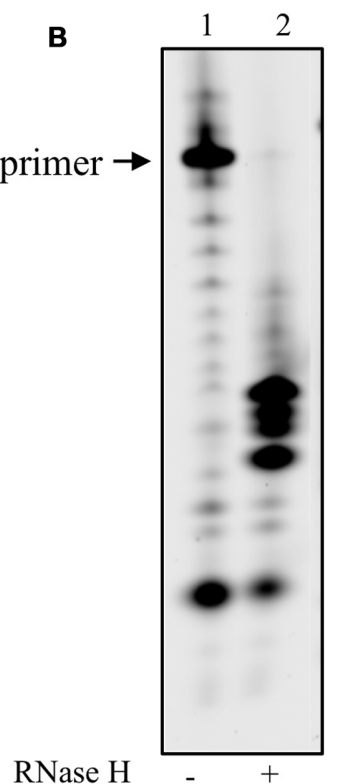

RNase H
Naïve DinB

C

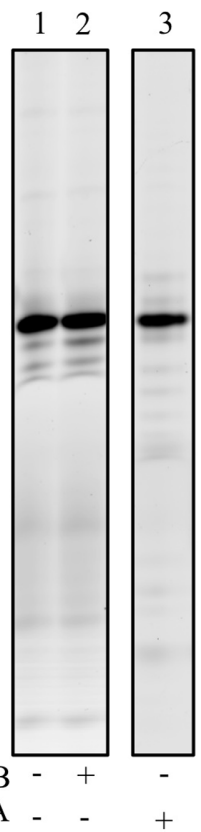

FIGURE 2 | RNA primers used in this study are stable, anneal adequately to the DNA template and no RNase contamination is detected in stocks of purified proteins. (A) DNA and RNA primers separated on acrylamide gels are quantified to determine the stability of the labeled primers. Percent full-length primer was calculated as the percent of total band intensity found in the full-length band (labeled RNA or DNA primer). As shown in the graph in the right hand side of the gel image, there are comparable levels of full-length primers indicating they are equally stable in the assay conditions. Error bars indicate mean \pm standard error. (B) RNase $\mathrm{H}$ digests only RNA-DNA hybrid molecules, therefore the RNA: DNA primer template mixes were left untreated $(-)$ or treated $(+)$ with $\mathrm{RNase} H$. The results of the experiments show that most of the RNA primer is annealed to the DNA template as only a negligible band of the full-length primer is observed in the $\mathrm{RNase} \mathrm{H}$ digestion of RNA primer annealed to DNA template. The products of the digestion are observed in the $(+)$ lane underneath of what it would have been the full-length primer band. (C) To test whether the

(Continued)

\section{FIGURE 2 | Continued}

protein stocks used had contaminating RNase activity, $0.6 \mu \mathrm{M}$ of naïve DinB or RecA protein is incubated with the labeled RNA primer annealed to DNA template in the absence of dNTPs. No degradation of the primer was observed as there is no difference between the $(-)$, no protein, lanes are the same as the $(+)$ lanes. These data indicate that the respective protein stocks are not contaminated with an RNase. All experiments were repeated three times and similar results are observed every time. Images are from representative gels. The products shown in the lane of $\operatorname{Rec} A(+)$, right hands side of $\mathrm{C}$, were separated on a different gel than the one shown for naïve DinB.

primers (Figure 1E). These data indicate that interaction with RecA further inhibits DinB's already poor ability to synthesize DNA using RNA primers.

\section{DinB's Poor RNA Primer Extension Is Not Due to RNA Primer Degradation, Poor Annealing, or RNase Contamination}

To ensure that DinB poor RNA primer extension was not due to a difference in concentration or degradation of the RNA primers, the un-annealed DNA or RNA primers were separated using denaturing gel electrophoresis (Figure 2A). The full-length band for either primer was quantified as the percent of full-length primer in relation to lower bands and found to be comparable (graph in Figure 2A).

We next sought to examine another possible technical explanation for the data in Figure 1: that the RNA primer is not efficiently annealing to the DNA template. Therefore, RNase $\mathrm{H}$ was used to digest the RNA primer annealed to the DNA template. Since RNase H only digests RNA-DNA hybrids, inefficient annealing would result in undigested RNA primer (similar to the undigested control, lane 1 in Figure 2B). However, we find only smaller fragments (lane 2 in Figure 2B) and negligible evidence of the full-length RNA primer after RNase $\mathrm{H}$ digestion, indicating that most of the RNA primer had successfully annealed to the DNA primer.

Finally, as an RNase contamination of the purified protein preparation could possibly account for poor RNA primer extension, we incubated purified naïve DinB or RecA with the RNA primer annealed to DNA template in the absence of dNTPs and found no visible RNA primer degradation, suggesting this possibility is unlikely (Figure 2C).

These data led us to conclude that naïve DinB's poor RNA primer extension (Figures 1B,D) arises from bona fide inefficient synthesis from an RNA primer.

\section{DinB Extension from an RNA Primer is Reduced by Addition of Unlabeled DNA primer:template with Little Effect on DinB Extension from a DNA Primer}

We measured the effect of adding increasing concentrations of unlabeled DNA: DNA on DinB extension from a labeled RNA primer annealed to the same DNA template (RNA*: DNA). We predicted that the unlabeled DNA: DNA should decrease the extension from the RNA*: DNA due to DinB's preference for DNA primers, while having less of an effect on DinB extension 

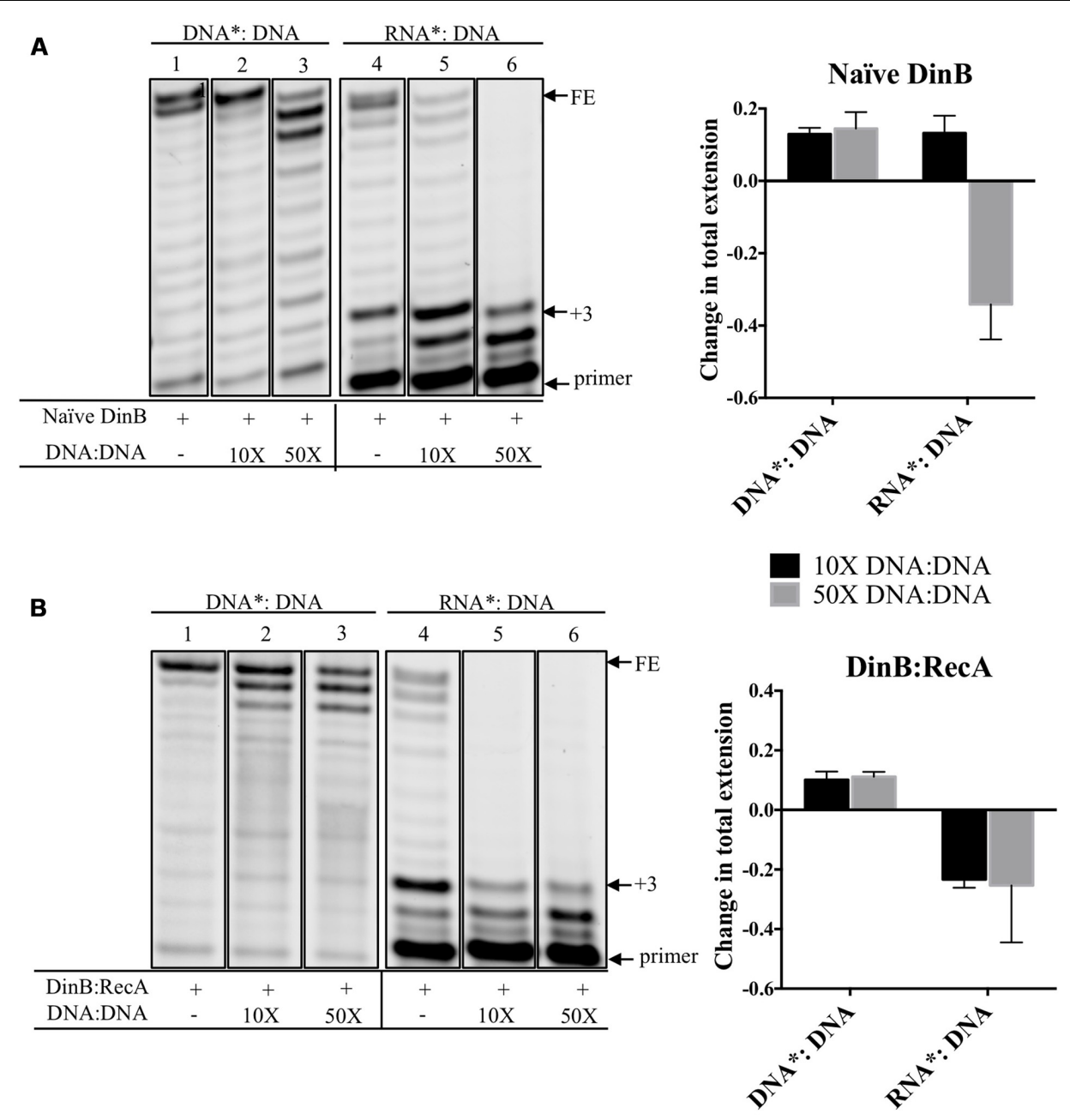

FIGURE 3 | Competition experiments using unlabeled DNA primer:template show that the extension from a labeled RNA primer is reduced for naïve DinB or DinB:RecA with little effect on the extension from a DNA primer. (A) Naîve DinB DNA primer extension assays are not competed by a 10 or 50 -fold excess of unlabeled DNA: DNA primer template as shown in the first three lanes. In contrast the RNA primer extension assays show competition with a 50-fold excess of the unlabeled DNA: DNA primer template. The quantification of the change in total extension is shown in the right hand side graph. The bars shown above zero indicate no change while the bars below zero indicate competition. (B) DinB:RecA was formed as indicated in Figure 1 legend. DinB:RecA DNA primer extension activity was unchanged by competing 10 or 50 -fold excess of the DNA: DNA primer template. This is shown in the first three lanes. The competition by the DNA: DNA on the RNA primer extension activity of DinB:RecA is evident with both a 10 or 50-fold excess. Quantification of total extension is described in Section "Materials and Methods." All experiments were performed in triplicate and comparisons were made of products separated on the same gel. Quantification is shown in the right hand side of the gel images. Images are of representative gels. Error bars indicate mean \pm standard error. DNA*: DNA, fluorescently labeled DNA primer annealed to DNA template; RNA*: DNA, fluorescently labeled RNA primer annealed to DNA template; DNA: DNA, unlabeled DNA primer annealed to unlabeled DNA template; FE, fully extended primer band; +3 , primer plus three nucleotide insertions band.

from a labeled DNA primer annealed to a DNA template (DNA*: DNA). Quantification of the data gathered from separating the extension products in a denaturing gel (lanes 4-6 in Figure 3A) indicate that the addition of 50 -fold higher concentration of DNA: DNA reduced naïve DinB's total extension from the RNA*: DNA by $\sim 34 \%$ (graph in Figure 3A). As predicted, the addition of DNA: DNA had little effect on the total extension of DinB on DNA*: DNA (lanes 1-3 in Figure 3A).

Because there is a larger difference in DinB:RecA's ability to synthesize from DNA versus RNA primers compared to naïve DinB, we predicted that smaller concentrations of competing DNA: DNA would be required to reduce DinB:RecA's extension on RNA*: DNA. Notably, addition of only 10-fold higher concentration of DNA: DNA reduced total extension of the RNA*: DNA by $\sim 23 \%$ (graph in Figure 3B), though total extension from DNA*: DNA is similar to that observed and quantified in naïve DinB (compare lanes $1-3$ in Figure 3A to lanes 1-3 in Figure 3B). These results support the assertion that DinB:RecA synthesizes using RNA primers even more poorly than naïve DinB and suggests that there might be a change in the DinB active site when interacting with RecA. This is consistent with our previous findings that interaction with RecA affects DinB function (Godoy et al., 2007; Cafarelli et al., 2013, 2014). 


\section{Naïve DinB and DinB:RecA Pausing on an RNA Primer is Independent of Template Sequence and Lesion}

From the experiments described above, we know that when both naïve DinB and DinB:RecA (1:1) extend from an RNA primer there is a clear accumulation of $\mathrm{a}+3$ insertion product (lane 4 Figure 1B and lane 2 in Figure 1D). This is not observed on the DNA primer (lane 2 Figure 1B and lane 1 in Figure 1D). To rule out the possibility that this accumulation is due to a template sequence effect, we changed the sequence of the template at the nucleotides opposite from the +3 insertion site from $C$ to $G$ (C3G DNA template, Supplementary Table 1). This sequence change had no effect on the accumulation of the +3 insertion product for either naïve $\operatorname{DinB}(\mathrm{C} 3 \mathrm{G}$ template, Figure 4A) or DinB:RecA (C3G template, Figure 4B). We also changed every purine in the template sequence to a pyrimidine (All pyr DNA template, Supplementary Table 1) and we observe no effect on the +3 insertion product regardless of whether we used naïve DinB (All pyr template, Figure 4A) or DinB:RecA (All pyr template, Figure $4 \mathrm{~B}$ ). These data indicate that the +3 insertion product accumulation is independent of template sequence.

Due to DinB's activity as a TLS polymerase, we determined whether both naïve DinB and DinB:RecA have the ability to bypass a lesion from a template that contained $3 \mathrm{~d}-\mathrm{meA}$ at the primer:template junction (Supplementary Table 1). We observed that there is lesion bypass, but the accumulation of the +3 insertion product for naïve DinB or for DinB:RecA (lesion template, Figures 4A,B respectively) occurs regardless of the template lesion indicating that the +3 pause is lesion independent.

The +3 insertion pause is reminiscent of one previously described for the derivative DinB(Y79L) (Jarosz et al., 2009) in experiments of lesion bypass. This pause was interpreted as being part of an important regulatory mechanism for TLS with cell survival consequences; strains with the plasmid-borne DinB(Y79L) are susceptible to DNA damage generated by the antibiotic nitrofurazone (Jarosz et al., 2009).

It is possible that during RNA primer extension DinB's active site resembles that of $\operatorname{DinB}(\mathrm{Y} 79 \mathrm{~L})$, in which tyrosine (Y) 79 has been changed to leucine $(\mathrm{L})$, resulting in a similar pause. Pausing and aborted DNA synthesis, like that predicted in the DinB(Y79L) variant (Jarosz et al., 2009), might represent a mechanism by which DinB is prevented from synthesizing on the lagging strand of DNA synthesis. This preferential activity suits the role of DinB as a specialized DNA polymerase with DNA damage tolerance activities.

\section{DISCUSSION}

DinB, the most evolutionarily conserved TLS DNA polymerase (Ohmori et al., 2001), is prone to causing mutations (Tang et al., 2000). Therefore, $\operatorname{din} B$ gene expression (Fernandez De Henestrosa et al., 2000; Courcelle et al., 2001; Khil and CameriniOtero, 2002; Friedberg et al., 2006) and DinB activity (Godoy et al., 2007; Cafarelli et al., 2013, 2014) are tightly regulated.

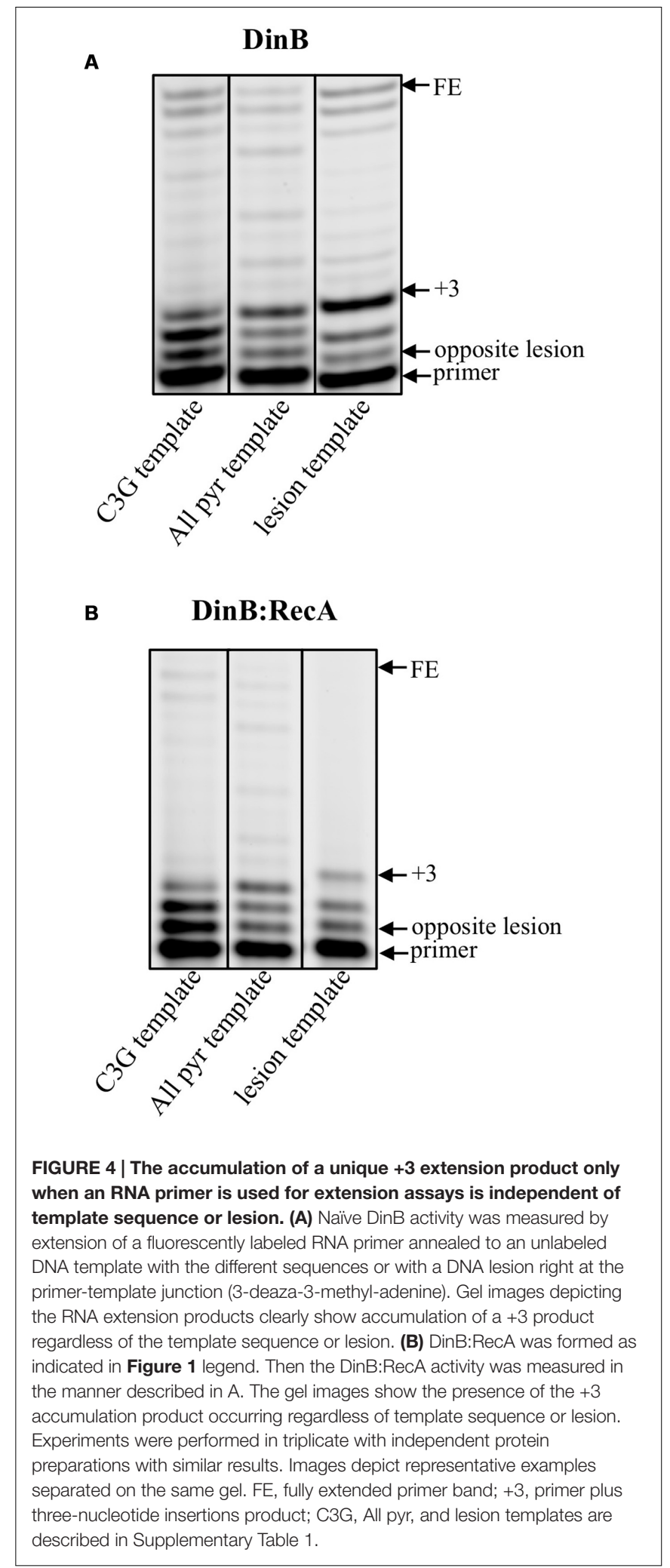

In particular, DinB activity is governed by protein-protein interaction with RecA and a dimer of UmuD (Godoy et al., 2007). The binding of these interacting partners visibly alters 
the mutagenic potential of DinB in vivo and in vitro (Godoy et al., 2007; Cafarelli et al., 2013, 2014). We have also established that RecA binds to DinB prior to UmuD and proposed that DinB interacting with RecA may occur more frequently than the DinB•RecA $\bullet \mathrm{UmuD}_{2}$ complex in vivo (Cafarelli et al., 2013). We have also shown that RecA interaction positively alters DinB fidelity (Cafarelli et al., 2014), which we presumed is due to a change in the DinB active site conformation upon binding to RecA.

We report here that DinB poorly extends from RNA primers (Figure 1). During non-DNA damaging conditions the affinity of the beta clamp for DinB, though lower than the affinity for DNA Pol III $\alpha$ (Heltzel et al., 2009, 2012), may be sufficient to prevent DinB from accessing the forming replication fork at RNA primers, even though DinB is present at a significantly higher concentration (Maki et al., 1985; Kim et al., 2001). We hypothesize that the drastically increased concentration of DinB upon DNA damage would overwhelm the affinity for the beta clamp allowing DinB access to the lagging strand. In fact, upon SOS induction, the dramatically higher concentration of $\operatorname{DinB}$ (Kim et al., 2001) slows the rate of replication by Pol III $\alpha$ (Tan et al., 2015), likely occurring at the lagging strand, suggesting that the elevated DinB intracellular concentration overwhelms the selectivity of the beta clamp and allows DinB to access the replication fork. Indeed, previous studies have shown that DinB slows replication by Pol III $\alpha$ specifically on the lagging strand (Indiani et al., 2009). We find that DinB:RecA synthesizes poorly using RNA primers compared to DNA primers beyond the third nucleotide insertion and that this poor synthesis is independent of template sequence or of a lesion (Figure 4). DinB:RecA (or DinB) would access the replication fork on the lagging strand, but would not efficiently synthesize from RNA primers providing a mechanism to slow down replication with a lowered mutagenic cost.

The pausing observed in DinB (or DinB:RecA) using an RNA primer (Figures 1, 3, 4) resembles that caused by a DinB variant, DinB(Y79L), which also pauses exactly three nucleotides after a template lesion (Jarosz et al., 2009). In the native DinB protein, the Y79 residue interacts with another aromatic residue, phenylalanine (F) 13, which in turn interacts with the incoming nucleotide (Nevin et al., 2015). During TLS, the loss of the large $\mathrm{Y}$ aromatic residue in $\operatorname{DinB}(\mathrm{Y} 79 \mathrm{~L})$ is hypothesized to cause a conformational change of the active site, which leads to the DinB pausing three nucleotides after encounter of a lesion (Jarosz et al., 2009; Nevin et al., 2015). It is remarkable that the use of an RNA primer results in a similar DinB pausing (Figures 1, 3, 4), suggesting the RNA primer may induce a similar active site conformation as that of $\operatorname{DinB}(Y 79 \mathrm{~L})$. Moreover, the DinB

\section{REFERENCES}

Benson, R. W., Cafarelli, T. M., Rands, T. J., Lin, I., and Godoy, V. G. (2014). Selection of $\operatorname{din} B$ alleles suppressing survival loss upon $\operatorname{din} B$ overexpression in Escherichia coli. J. Bacteriol. 196, 3023-3035. doi: 10.1128/JB. 01782-14 interaction with RecA would stabilize this change. The pausing observed in the $\operatorname{DinB}(\mathrm{Y} 79 \mathrm{~L})$ variant is hypothesized to be part of an abortive TLS mechanism, which would lead to a futile cycle of DinB pausing and DNA polymerase III excision repair (Jarosz et al., 2009). It is possible that native DinB undergoes a similar cycle of abortive synthesis with an RNA primer. This mechanism could account for the sickness and lethality that has been observed upon DinB overproduction (Benson et al., 2014).

The data reported here identify a pausing in DinB's DNA synthesis while using an RNA primer. This novel finding represents an important potential mechanism for preventing the high intracellular concentration of DinB from inducing unnecessary mutagenesis.

\section{AUTHOR CONTRIBUTIONS}

TT: designed and performed experiments, analyzed data, and wrote paper; IL: performed and designed RecA protein purification experiments and analyzed data; VB: performed initial RNA primer extension experiments; TC: designed initial experiments and analyzed data; VG: designed experiments, analyzed data and wrote paper.

\section{FUNDING}

National Institute of General Medical Sciences (RO1GM088230 to VG). Funding for open access charge: NIGMS (RO1GM088230 to $\mathrm{VG})$.

\section{ACKNOWLEDGMENTS}

We are grateful to D. Jarosz (Stanford University) and K. Knight (University of Massachusetts Medical School) for critical reading of the manuscript. We would like to thank S. Gradia for plasmid 29653: pET His6 TEV LIC cloning vector (1B) and Janice Pata (Wadsworth Center, NYS Department of Health) for the generous contribution of purified DNA polymerase Kappa. We would also like to thank members of the Godoy Lab for critically reading the manuscript.

\section{SUPPLEMENTARY MATERIAL}

The Supplementary Material for this article can be found online at: http://journal.frontiersin.org/article/10.3389/fmicb. 2017.00288/full\#supplementary-material

Beuning, P. J., Simon, S. M., Godoy, V. G., Jarosz, D. F., and Walker, G. C. (2006). Characterization of Escherichia coli translesion synthesis polymerases and their accessory factors. Methods Enzymol. 408, 318-340. doi: 10.1016/ S0076-6879(06)08020-7

Bull, H. J., Lombardo, M. J., and Rosenberg, S. M. (2001). Stationary-phase mutation in the bacterial chromosome: recombination protein and DNA 
polymerase IV dependence. Proc. Natl. Acad. Sci. U.S.A. 98, 8334-8341. doi: 10.1073/pnas.151009798

Cafarelli, T. M., Rands, T. J., Benson, R. W., Rudnicki, P. A., Lin, I., and Godoy, V. G. (2013). A single residue unique to DinB-like proteins limits formation of the polymerase IV multiprotein complex in Escherichia coli. J. Bacteriol. 195, 1179-1193. doi: 10.1128/JB.01349-12

Cafarelli, T. M., Rands, T. J., and Godoy, V. G. (2014). The DinB*RecA complex of Escherichia coli mediates an efficient and high-fidelity response to ubiquitous alkylation lesions. Environ. Mol. Mutagen. 55, 92-102. doi: 10.1002/em.21826

Chen, Z., Yang, H., and Pavletich, N. P. (2008). Mechanism of homologous recombination from the RecA-ssDNA/dsDNA structures. Nature 453, 489. doi: 10.1038/nature06971

Chintapalli, S. V., Bhardwaj, G., Babu, J., Hadjiyianni, L., Hong, Y., Todd, G. K., et al. (2013). Reevaluation of the evolutionary events within recA/RAD51 phylogeny. BMC Genomics 14:240. doi: 10.1186/1471-2164-14-240

Cirz, R. T., Chin, J. K., Andes, D. R., de Crecy-Lagard, V., Craig, W. A., and Romesberg, F. E. (2005). Inhibition of mutation and combating the evolution of antibiotic resistance. PLoS Biol. 3:e176. doi: 10.1371/journal.pbio.0030176

Courcelle, J., Khodursky, A., Peter, B., Brown, P. O., and Hanawalt, P. C. (2001). Comparative gene expression profiles following UV exposure in wild-type and SOS-deficient Escherichia coli. Genetics 158, 41-64.

Fernandez De Henestrosa, A. R., Ogi, T., Aoyagi, S., Chafin, D., Hayes, J. J., Ohmori, H., et al. (2000). Identification of additional genes belonging to the LexA regulon in Escherichia coli. Mol. Microbiol. 35, 1560-1572. doi: 10.1046/j. 1365-2958.2000.01826.x

Friedberg, E., Walker, G., Siede, W., Rd, W., Ra, S., and Ellenberger, T. (2006). DNA Repair and Mutagenesis. Washington, DC: ASM Press.

Godoy, V. G., Jarosz, D. F., Simon, S. M., Abyzov, A., Ilyin, V., and Walker, G. C. (2007). UmuD and RecA directly modulate the mutagenic potential of the $Y$ family DNA polymerase DinB. Mol. Cell 28, 1058-1070. doi: 10.1016/j.molcel. 2007.10.025

Goodman, M. F. (2002). Error-prone repair DNA polymerases in prokaryotes and eukaryotes. Annu. Rev. Biochem. 71, 17-50. doi: 10.1146/annurev.biochem.71. 083101.124707

Goodman, M. F., and Woodgate, R. (2013). Translesion DNA polymerases. Cold Spring Harb. Perspect. Biol. 5:a010363. doi: 10.1101/cshperspect.a010363

Heltzel, J. M., Maul, R. W., Scouten Ponticelli, S. K., and Sutton, M. D. (2009). A model for DNA polymerase switching involving a single cleft and the rim of the sliding clamp. Proc. Natl. Acad. Sci. U.S.A. 106, 12664-12669. doi: 10.1073/ pnas.0903460106

Heltzel, J. M., Maul, R. W., Wolff, D. W., and Sutton, M. D. (2012). Escherichia coli DNA polymerase IV (Pol IV), but not Pol II, dynamically switches with a stalled Pol III* replicase. J. Bacteriol. 194, 3589-3600. doi: 10.1128/JB.00520-12

Horii, T., Ogawa, T., Nakatani, T., Hase, T., Matsubara, H., and Ogawa, H. (1981). Regulation of SOS functions: purification of E. coli LexA protein and determination of its specific site cleaved by the RecA protein. Cell 27(3 Pt 2), $515-522$.

Indiani, C., Langston, L. D., Yurieva, O., Goodman, M. F., and O’Donnell, M. (2009). Translesion DNA polymerases remodel the replisome and alter the speed of the replicative helicase. Proc. Natl. Acad. Sci. U.S.A. 106, 6031-6038. doi: 10.1073/pnas.0901403106

Indiani, C., Patel, M., Goodman, M. F., and O'Donnell, M. E. (2013). RecA acts as a switch to regulate polymerase occupancy in a moving replication fork. Proc. Natl. Acad. Sci. U.S.A. 110, 5410-5415. doi: 10.1073/pnas. 1303301110

Jarosz, D. F., Cohen, S. E., Delaney, J. C., Essigmann, J. M., and Walker, G. C. (2009). A DinB variant reveals diverse physiological consequences of incomplete TLS extension by a Y-family DNA polymerase. Proc. Natl. Acad. Sci. U.S.A. 106, 21137-21142. doi: 10.1073/pnas.0907257106

Jarosz, D. F., Godoy, V. G., Delaney, J. C., Essigmann, J. M., and Walker, G. C. (2006). A single amino acid governs enhanced activity of DinB DNA polymerases on damaged templates. Nature 439, 225-228. doi: 10.1038/ nature 04318

Kath, J. E., Jergic, S., Heltzel, J. M., Jacob, D. T., Dixon, N. E., Sutton, M. D., et al. (2014). Polymerase exchange on single DNA molecules reveals processivity clamp control of translesion synthesis. Proc. Natl. Acad. Sci. U.S.A. 111, 76477652. doi: 10.1073/pnas.1321076111
Khil, P. P., and Camerini-Otero, R. D. (2002). Over 1000 genes are involved in the DNA damage response of Escherichia coli. Mol. Microbiol. 44, 89-105. doi: 10.1046/j.1365-2958.2002.02878.x

Kim, S. R., Matsui, K., Yamada, M., Gruz, P., and Nohmi, T. (2001). Roles of chromosomal and episomal dinB genes encoding DNA pol IV in targeted and untargeted mutagenesis in Escherichia coli. Mol. Genet. Genomics 266, 207-215. doi: $10.1007 / \mathrm{s} 004380100541$

Konola, J. T., Guzzo, A., Gow, J. B., Walker, G. C., and Knight, K. L. (1998). Differential cleavage of LexA and UmuD mediated by recA Pro67 mutants: implications for common LexA and UmuD binding sites on RecA. J. Mol. Biol. 276, 405-415. doi: 10.1006/jmbi.1997.1531

Little, J. W., Edmiston, S. H., Pacelli, L. Z., and Mount, D. W. (1980). Cleavage of the Escherichia coli lexA protein by the recA protease. Proc. Natl. Acad. Sci. U.S.A. 77, 3225-3229. doi: 10.1073/pnas.77.6.3225

Maki, H., Horiuchi, T., and Kornberg, A. (1985). The polymerase subunit of DNA polymerase III of Escherichia coli. I. Amplification of the dnaE gene product and polymerase activity of the alpha subunit. J. Biol. Chem. 260, 12982-12986.

Maor-Shoshani, A., and Livneh, Z. (2002). Analysis of the stimulation of DNA polymerase V of Escherichia coli by processivity proteins. Biochemistry 41, 14438-14446. doi: 10.1021/bi0262909

Nevin, P., Engen, J. R., and Beuning, P. J. (2015). Steric gate residues of Y-family DNA polymerases DinB and pol kappa are crucial for dNTP-induced conformational change. DNA Repair (Amst) 29, 65-73. doi: 10.1016/j.dnarep. 2015.01.012

Nohmi, T. (2006). Environmental stress and lesion-bypass DNA polymerases. Annu. Rev. Microbiol. 60, 231-253. doi: 10.1146/annurev.micro.60.080805. 142238

Ohmori, H., Friedberg, E. C., Fuchs, R. P., Goodman, M. F., Hanaoka, F., Hinkle, D., et al. (2001). The Y-family of DNA polymerases. Mol. Cell 8, 7-8. doi: 10.1016/S1097-2765(01)00278-7

Salles, B., and Paoletti, C. (1983). Control of UV induction of recA protein. Proc. Natl. Acad. Sci. U.S.A. 80, 65-69. doi: 10.1073/pnas.80.1.65

Studier, F. W. (2005). Protein production by auto-induction in high density shaking cultures. Protein Expr. Purif. 41, 207-234. doi: 10.1016/j.pep.2005. 01.016

Tan, K. W., Pham, T. M., Furukohri, A., Maki, H., and Akiyama, M. T. (2015). Recombinase and translesion DNA polymerase decrease the speed of replication fork progression during the DNA damage response in Escherichia coli cells. Nucleic Acids Res. 43, 1714-1725. doi: 10.1093/nar/gkv044

Tang, M., Pham, P., Shen, X., Taylor, J. S., O’Donnell, M., Woodgate, R., et al. (2000). Roles of E. coli DNA polymerases IV and V in lesion-targeted and untargeted SOS mutagenesis. Nature 404, 1014-1018. doi: 10.1038/ 35010020

Thomason, L. C., Costantino, N., and Court, D. L. (2007). E. coli genome manipulation by $P 1$ transduction. Curr. Protoc. Mol. Biol. Chapter 1, Unit1.17. doi: 10.1002/0471142727.mb0117s79

Vidal, A. E., Kannouche, P., Podust, V. N., Yang, W., Lehmann, A. R., and Woodgate, R. (2004). Proliferating cell nuclear antigen-dependent coordination of the biological functions of human DNA polymerase iota. J. Biol. Chem. 279, 48360-48368. doi: 10.1074/jbc.M406511200

Wagner, J., Fujii, S., Gruz, P., Nohmi, T., and Fuchs, R. P. (2000). The beta clamp targets DNA polymerase IV to DNA and strongly increases its processivity. EMBO Rep. 1, 484-488. doi: 10.1093/embo-reports/kvd109

Yang, W. (2003). Damage repair DNA polymerases Y. Curr. Opin. Struct. Biol. 13, 23-30. doi: 10.1016/S0959-440X(02)00003-9

Conflict of Interest Statement: The authors declare that the research was conducted in the absence of any commercial or financial relationships that could be construed as a potential conflict of interest.

Copyright (c) 2017 Tashian, Lin, Belt, Cafarelli and Godoy. This is an open-access article distributed under the terms of the Creative Commons Attribution License (CC BY). The use, distribution or reproduction in other forums is permitted, provided the original author(s) or licensor are credited and that the original publication in this journal is cited, in accordance with accepted academic practice. No use, distribution or reproduction is permitted which does not comply with these terms. 